\title{
Toward A Sustainable Clean Energy Future: Lesson from Chinese Intellectual Property Litigations
}

\author{
Yujing Yang1, a Miaomiao Chen², b \\ ${ }^{1}$ Tan Kah Kee College of Xiamen University, Zhangzhou 363105, China; \\ ${ }^{2}$ Guangxi University for Nationalities, Guangxi 530006, China. \\ ayujingyang@xujc.com, bmiaomiao4562@163.com
}

\begin{abstract}
Keywords: Clean Energy, Intellectual Property Litigation, Technology Transfer, China, Climate Change.
\end{abstract}

\begin{abstract}
A well-functioning intellectual property (IP) regime plays an important role when the country pursuits innovation and low-carbon society as well. Though such a proposal can be applied to any nation or society, China provides an excellent experiment for the emerging economy countries in the transforming society. A series of IP litigations between the Chinese company SINOVEL and the U.S Company American Superconductor in terms of clean energy technologies (CETs) trade raise the contemporary debates over IP and climate change. Based on the empirical study and data evidence, this paper explores the characteristics and trends of IP litigations in Chinese CET market. Within the litigations, the multinational enterprises are the main players; and as a package strategy, the legal actions cover patent, copyright and trademark, commercial secret, with remedies and injunctions. However, antitrust has not become the main strategy against IP abuse in Chinese CETs market. And forum shopping is challenging Chinese judicial system when CETs industry blooms in the emerging country. This paper argues the IP maximalist trend among some developed countries and the functions of IP in CETs industry should not only focus on trade but also need to have the social and environmental concerns in the content of climate change. It is therefore suggested that the function of IP should primarily promote technology transfer. It is further suggested that the overemphasis on IPRs not innovation may potentially undermine not only the dissemination of CETs but also impair the effect of climate change mitigation globally.
\end{abstract}

\section{Introduction}

As the largest exporter of trade goods and GHG emitter in the world, China has the commitment of mitigating climate change. In 2009 China has issued the development agenda to reduce the national carbon dioxide emissions per unit GDP $40-45 \%$ by 2020 from a 2005 baseline and has aimed to achieve the goal of 15 per cent of non-fossil fuel energy by 2020. These commitments require China paving the way for the innovation and technology transfer of clean energy rapidly and efficiently. And as the prevailing practice in modern innovative countries, IP system plays a critical role in the clean energy innovation campaign in China. Indeed, Chinese IP law and policy have aggressively developed over the three decades. Three fundamental IP laws, which are Patent Law, Copyright Law, and Trade Law have been revised respectively in 2008, 2010 and 2013. What's more, China has become the largest country in patent application and trade mark application.

However, China is not in the top countries in terms of clean energy innovation, although she is the main manufacturer and assembler of the clean industry. The CETs innovation is currently dominated by OECD countries, which are six developed countries of the United States, Japan, Germany, United Kingdom, France and South Korea, accounting for almost 80 per cent of all patent applications in the CETs. [1] Also, according to the annual Report of China's Intellectual Property Development in 2015, compared with the IP system environment, the contribution of China's IP market environment and cultural environment is obviously insufficient and needs to be optimized. [2] In the context of severe challenge of climate change and the huge market demand, different industrial advantages and concerns lead to IP disputes in the CET industry. IP litigations in China among clean CET companies have 
attracted considerable concerns and indeed, scrutiny, on its trade and intellectual property rights (IPRs) regime in recent years.

\section{Wind Turbine IP litigation between AMSC and SINOVEL}

\subsection{Background: climate change commitment v. intellectual property rights}

There are tensions between climate change and intellectual property due to the CET transfer, which is one of the four important pillars of United Nations Framework Convention on Climate Change (UNFCCC). However, some countries argue that Agreement on Trade-Related Aspects of Intellectual Property Rights (TRIPs) does not provide effective mechanism to facilities the global CET transfer. Most of the potential CET receivers and users are in developing countries, who are calling for innovate the IP system. On the contrary, some developed nations who are the holders of mainly clean energy IP, emphasize to prevent any weakening of protection of IPRs related to CET. The polarized positions characterize the debate on climate change commitment and IPRs. This diverse in international legal framework also reflects on the CET trade in the world.

Indeed, the clean energy innovation is leading the U.S. green economy, but also has a positive impact on the country to participate in the international clean energy competition. In 2011, U.S. has reformed the Patent Law and launched the fast green mechanism for facilitating the green patent deployment. The U.S. patents for CET in 2014 were at an all-time high of 3609, which was 434 more than 2013 bringing clean energy patents into record territory. And this gain more than tripled the previous year-to year increase. [3] The overwhelming green patent ownership shows that IP is not only the basic precondition and comparative advantage to absorb investment but also the defensive weapon to restrict the competitors' entry into the emerging market. [4]

\subsection{Introduction of the IP litigations}

American Superconductor (AMSC) is an American energy technologies company based in Massachusetts with operations in Asia, Australia, Europe and North America. AMSC describes itself as generating the ideas, technologies and solutions that meet the world's demand for smarter, cleaner... better energy. AMSC provided software code for controlling wind turbines and power converter for Sinovel Wind Group Company (SINOVEL), which is the main wind turbine manufacturer in China and shared the second largest market in the world by 2011.SINOVEL was also the largest customer of AMSC, which once accounted for more than 75\% sales of AMSC. From 2011, Suzhou AMSC, (to avoid confusion, we refer to the subsidiary AMSC in Suzhou and the parent as AMSC) in China launched a series of IP lawsuits against SINOVEL, alleging that its software source code and binary code are misappropriated by SINOVEL. It is widely known that IPR still remains among top United States Trade Representative (USTR) priorities for China during the years (2013 USTR Report to Congress). These lawsuits grasped the attentions of not only the enterprises but also the governments between China and the U.S. since it was treated as a barometer to test IP enforcement in China in the emerging clean energy industry.

\subsubsection{The IP litigations outside China}

Before the legal actions in China, AMSC has initiated some criminal lawsuits versus SINOVEL in Austria and the United States respectively. AMSC filed a criminal case against its former employee in Austria court, alleging that this person committed to passing upgraded version of AMSC's code to SINOVEL for remuneration. AMSC also believed that the unauthorized use of the software code allowed SINOVEL to add a low voltage ride through function to its 1.5 -megawatt turbine crucial to meet upgraded Chinese grid requirements. The former employee pled guilty and was sentenced for a year in jail and two years of probation. Furthermore, the criminal act committed by the accused constituted the offence of civil claim, which caused damage in the amount of at least $\not \subset 6$ million. After the legal action in Austria, in 2012, the U.S. Department of Justice filed an indictment in federal court in Wisconsin alleging that two of SINOVEL's employees and a former AMSC's employee conspired to trade secret theft and criminal copyright infringement. The technologies involved AMSC's source of code, software, equipment designs relating to the wind turbines and electricity grid, 
which alleged more than $\$ 800$ million damages. SINOVEL contested jurisdiction and motioned to quash a summons, which was denied by the district court in July 2013. SINOVEL then appealed to the Seventh Court of Appeal to reverse a lower court ruling and quash a summons. In July 23, 2015, the U.S. Court of Appeal issued a precedential opinion, concluding that it lacked appellate jurisdiction on a foreign defendant by way of its U.S. based subsidiary.

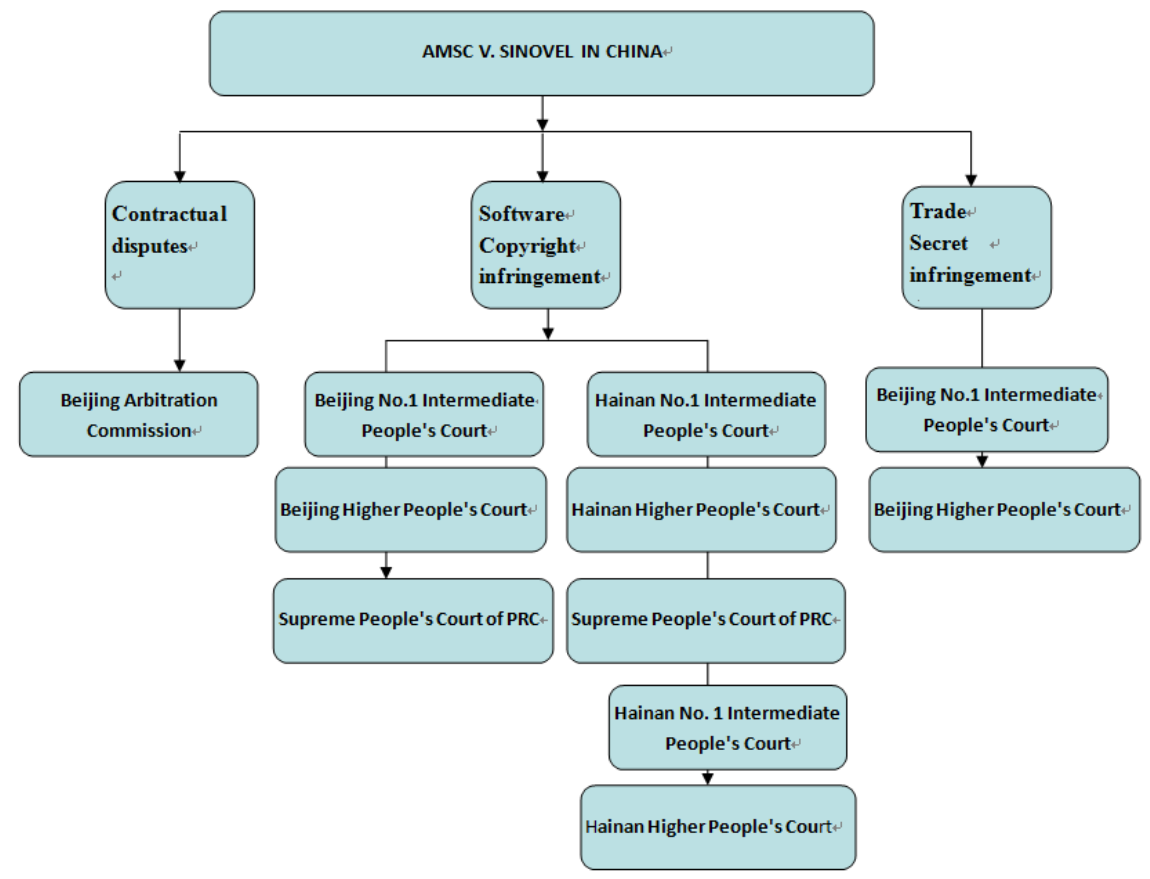

Table 1: The intellectual property litigations between AMSC and SINOVEL in China

\subsubsection{The IP litigations in China}

AMSC commenced several legal actions against SINOVEL in China. In 2011, AMSC filed a claim at the Beijing Arbitration Commission that SINOVEL refused to pay past due amounts for components, seeking for $\$ 70$ million compensation and performing the existing contracts worth about $\$ 700$ million. Then, SINOVEL launched the counterclaim, requesting for $\$ 800$ million in economic losses and \$ 370 million compensation due to the unqualified products provided by AMSC. In 2012, SINOVEL launched another case, claiming that AMSC failed to offer the qualified grid coding to meet Chinese standard of lower voltage ride through function according to the contracts.

Apart from the cases in arbitration, AMSC involved three separate actions in various forums in China. The first software copyright case suited in the Hainan No. 1 Intermediate People's Court was dismissed due to the jurisdictional grounds. AMSC appealed to the Hainan Higher People's Court and was denied by the higher count again. Then the Supreme People's Court repealed the ruling of the lower courts, favoring to AMSC, and remanding for retrial by the Hainan No. 1 Intermediate People's Court that dismissed all the claims of AMSC. It was appealed to the Hainan Higher People's Court again and was rejected finally, maintaining the former decision in Aug.8, 2016. The key issue in the case is whether SINOVEL infringed the software copyright of AMSC. The court held that the evidence is invalid due to illegal means to collect the evidence as well as the notary's procedural illegal proof to the infringement according to the Notarization Law. In addition, the inquiry transcript of the former employee of AMSC was collected outside China and lacked of other evidence to supported, therefore it was not acceptable. The Criminal Judgment of Austria certified by the Chinese Embassy in Austria cannot be recognized and enforced considering the evidence was not provided in accordance with the Civil Procedure Law.

The second software copyright case suited in Beijing No. 1 Intermediate People's Court also went through the hearings of three courts. After the Jurisdiction objection of SINOVEL was dismissed, the Beijing Higher People's Court upheld the ruling of the lower court, affirming that the dispute of software copyright did not fall under "all disputes relating to the execution of this contract" therefore 
the court has the jurisdiction. SINOVEL applied for retailing the case to the Supreme Court, which reaffirmed the decision of the Beijing Higher People's Court.

In the third action regarding trade secrets, AMSC claimed for $\$ 450$ million, which is the highest amount of IP litigation case in China so far. The Beijing No. 1 Intermediate People's Court dismissed SINOVEL's claim of Jurisdiction objection. The Beijing Higher People's Court upheld the ruling of the lower court and affirmed the trade secrets dispute does not fall under the arbitration clause between the parties.

\section{Characteristics and Trends of Clean energy IP Litigations in China}

As the clean energy industry is the emerging business, most of the innovative companies have secured a lot of protected IP to significant commercial advantage, IPs are treated as the important financial and technological competitiveness and the critical legal instruments. The litigation between AMSC and SINOVEL is a slice to observe the obstacles when clean energy technology transfer between China and the world. Therefore it is significant to explore the characteristics and trends of IP lawsuits among Chinese and foreign clean energy companies.

\subsection{Multinational companies are the main players of clean energy IP litigations}

In 2014, the U.S. was the leader of CET innovation, with 1504 green patents granted. Japan took second place, with 696 patents, followed by Korea, Germany, Denmark, and Taiwan. It is obviously that China is not in the clean energy innovation IP list, meanwhile China has leaded the clean energy industry investment in the world in the recent years. As 2017 begins, China has become the most important player in investment of clean energy by 60 percent to reach a record $\$ 32$ billion. ${ }^{[5]}$ Most of the innovative foreign companies have their IP deployment in China, with setting up the affiliates, for instance, AMSC has authorized the software copyright license to its subsidiary in Suzhou. The top global clean energy patent holders, Toyota, General Motors and etc have speeded up their IP deployment in Chinese market. Also, the multinational companies use IP litigation to consolidate their market position and intent to create legal favorable jurisprudence for their further development. For example, in 2014 Tesla wined the eco-trademark troll lawsuit in Chinese market to create its sound market prospects. In addition, multinational companies have the capacity, energy and experience to carry out the time-money consuming legal actions, compared with those domestic companies. In the case of AMSC v. SINOVEL, it takes more than six years for two parties to address the disputes through judicial proceedings.

\subsection{Multi-pronged Litigation approach is a key strategy}

Despite the judiciary is independent in different nations, the IP litigation has the large country effect. For example, the IP case on green cars between Toyota Motor v. Paice, has been cited in a range of other patent disputes, particular dealing with expert evidence, patent infringement, and with remedies and the grant of injunction and copyright disputes. ${ }^{[6]}$ The patent infringement litigations between General Electric and Mitsubishi in the U.S. wind turbine industry has obviously shown that the IP litigation strategy covers multi-pronged approaches, including but not limit to patent infringement, 337 investigation, antitrust. The patent litigations in the United States and European have a significant impact globally, especially in the clean energy market of simultaneous development market, such as China, India and Brazil. It is obviously to see in AMSC v. SINOVEL that a series of cases combine with the infringements of copyright, commercial secrets and contractual disputes. This multi-pronged litigation strategy in the relatively competitive wind turbine industry has been learned by other clean energy industries which are still in a free landscape, such as in the field of biofuels, smart grids, and carbon capture and storage.

\subsection{Antitrust has not yet become the key tool to against IP litigations abused}

According to the Article 40 of TRIPs, it requires to control of anti-competitive practices in contractual licenses. However firms may rely on restrictive contracts, trade secrets or technological controls over technical data. Know-how and other information necessary to effectively utilize and adapt CETs may be protected through shrink-wrap licenses or technology protection measurements. 
These "soft" legal instruments can impose significant costs on access to CETs. ${ }^{[7]}$ In the IP licensing practices between Chinese licensee and foreign licensor, the agreements are signed with conditions, which are obviously against competition. For example, it should be considered as a substantive breach of the agreement if the licensee obtains from a third party the same or similar equipment with the licensed technology without the confirmation of the licensor, or if the licensee carries out the follow-up research or development based on the licensed technology without written notice to the licensor. In some mature industries, such as in the smart phone and automobile, antitrust is the key instrument to control IP abuse. Since the Chinese Anti-monopoly Law came into force in 2008, there are a series of anti-monopoly cases, which the most of the investigated companies have been fined. Within these cases, IP abuse has been realized. Also, it is obviously shown in the case of General Electric v. Mitsubishi that antitrust is the significant measure not only as the judicial relief for clean energy companies, but also a commercial means to restrict competitors to enter the new energy market. With the development of Chinese antitrust law and the flourished clean energy patent filing, this scene will also be seen in the new market soon.

\subsection{Forum shopping is challenging the IP judicial system}

In the international level, the regulation of IP takes place in a range of forums, which are mainly WIPO, and WTO. The resilience of international forums enables the states to pursue their interests maximized from forum shopping. The same situation happened in nations. In the cases of General Electric v. Mitsubishi, International Trade Commission, Federal District Courts and Circuit Court are the forums to deal with the disputes. It is the same in Toyota Motor v. Paice, which seek to the settlements in Eastern District Court, Federal Circuit Courts, the Supreme Court and International Trade Commission. In the cases of AMSC v. SINOVEL, the forums are the courts and arbitration center in Beijing, the courts in Hainan, even the courts in US and Austria. Within the forums, the procedural issues are questioned more often than the substantive issues.

The global minimum IP protection standards of TRIPs were implemented in the member states. However, the enforcement of the minimum standard in different country may vary. Even in the U.S. which has the high standards of IP protection, the trails of IP litigation still exist unjustified rates, such as Texas. ${ }^{[8]}$ China has established the IP courts in Beijing, Shanghai and Guangzhou respectively, which enhance the capacity to address IP disputes. However, forum shopping is challenging not only the companies bus also the judicial system to involve in the global clean energy trade war.

\section{Lessons from the Clean Energy IP Litigations}

\subsection{The argument between IP and CETs transfer remains open}

In 2007, the ICTSD reported that for the CETs access of developing countries, IPs are the POSSIBLE barriers, difficulty in obtaining PV, biofuel and wind respectively. And it seems UNLIKELY to be significant IP barriers to developing nation. [9] Many uncertain expressions in the report means that the situation may vary within the rapid development of the new industry. In 2010, another relative ICTSD report reveals that the expansion of patenting activity in clean industry does not automatically mean an increase in technology transfer. Meanwhile, clean energy patent boom sets stage for IP wars. It is regularly occurred in most CETs, including wind power, solar power and etc. ${ }^{[1]}$ The IP litigation between AMSC and SINOVEL is the empirical study to exam the argument on IP and CETs transfer. In another clean energy IP litigation, China Environmental Project Tech Inc. (CEPT) took eight years to against Japan FKK and Huayang Electronic Co. Ltd for infringement of a patented process of using seawater for flue gas desulphurization. The chairman of the board of CEPT lamented that the company lost the time and the market, although they won the case. Many Chinese clean energy firms are suited due to IP infringements, which cover a wide range from patent, trade mark, copyright, to trade secrets.

\subsection{The evidence of IP maximalism}

In the context of the IP cases between clean energy firms, it is worth reasserting the IP maximalists that IPRs have not served for CET transfer effectively. The innovative companies are struggling to 
cope with lawsuits with more energy and money, which declines their competitiveness and is inadvertently engaged in R\&D. For instance, after the series of legal actions, SINOVEL has to revoke its eight foreign companies due to the business obstacles, including the IP barriers. A number of academics and scholars have questioned the functions of IP as an incentive to address climate change and global warming. ${ }^{[10]}$ As the leading country in CET, the U.S. has expanded the IP protection from TRIPs minimum to TRIPs to TRIPs-plus gradually, which raised the cost of technology transfer globally.

\subsection{Make clean energy sustainable in the future}

The center of the clean energy universe has shifted decisively from "North" to "South". [11] And a group of five powerful nations, so-called BRICS countries (Brazil, Russia, India, China and South Africa) has officially created a new financial and political institution, which may facilities the CETs transfer among the countries. Indeed, China is poised for an IP transition, which was pointed as the next most important filing destination for clean energy patents in the field of solar power and wind power. ${ }^{[1]}$ And in the IP-intensive industry, China is also in the rapid transition period from a CETs receiver to a CETs creator in the following decade. The functions of IP should be challenged with clean energy revolution. Meanwhile, since the cost of CETs is cheaper compared to those from developed countries and the technology absorption capacity is closer to the other developing countries, China may gradually become the main provider of CETs to the least developing countries in the coming decades and may assume the dual identity of CETs creator and CETs producer. For instance, China was the largest owner of patents in emerging economics for wind and solar technology. Therefore, it is important to balance the functions of IP, to avoid the high-cost of litigations and put more focus on technology transfer and knowledge dissemination of CETs, which are essential needed to address climate change.

\section{Summary}

As the global public good, climate change requires widely disseminating CETs. However as the legally and monopoly private right, IP raises the transaction cost in elimination of global warming in the way of IP litigations nationally and internationally. Indeed, as a part of social contract, IP should have more environmental concerns and social considerations, compared with as a simply economic incentive and private property rights. In fact, climate change brings the significant legal challenges and opportunities. One of the essential results involved the IP litigations among the firms in developed and developing countries. As the largest greenhouse gas emitter and clean energy investor, China is keen for access to clean energy to combat global warming. Also, China has launched a series of law and policies to encourage clean energy innovation. However, Chinese clean energy companies, law firms, government departments, even judicial system are not ready in responding the changes. A series of disputes between Chinese clean energy firm and foreigner-invested company highlight the tension between climate change and intellectual property. The IP maximalists should be challenged within the context of not only TRIPS but also UNFCCC. And if the IP trade war on clean energy cannot be addressed in a sustainable ways, it is hardly to achieve the goal of climate change mitigation from the CETs transfer globally.

\section{References}

[1]. UNEP, EPO, ICTSD. Final Report of Patents and Clean Energy: Bridging the Gap between Evidence and Policy.Munich: EPO Graphic Design, 2010, p.9.

[2]. China's intellectual property development Report in 2015.China Patent and Trademarks. (2016) No.3, p. 54.

[3]. Cleantech Group at Heslin Rothenberg Farley \& Mesiti P.C. The Green Patent Growth Index in 2014. 
[4]. Yujing Yang. Characteristics and Trends of the U.S. Clean Energy Patent Litigations and Its Implications for China[J].Journal of Beijing Insititute ofTechnology.Vol.15 (2013) No.1, p.123-128.

[5]. Joel Paul Joffe, Ranping Song, China is leaving the U.S. behind on clean energy invetment. World Resources Institute.Jan.6.2017.

[6]. Matthew Rimmer, Intellectual Property and Climate Change. Edward Elgar Publishing Limited,2011, p. 232.

[7]. Keith E.Maskus, Ruth L.Okediji, Intellectual Property Rights and International Technology Transfer to Address Climate Change: Risks, Opportunities and Policy Options, ICTSD report, 2010, p. 38.

[8]. Chief Judge Randall R. Rader, The State of Patent Litigation, The Federal Circuit Bar Journal. Vol.21 (2013) No.3, p. 331-345.

[9]. John Barton, Intellectual Property and Access to Clean Energy Technologies in Developing Countries: An Analysis of Solar Photovoltaic, Biofuel and Wind Technologies, Geneva: ICTSD report, 2007,p. 18.

[10]. Ahmed Abdel-Latif. Intellectual Property Rights and Green Technologies from Rio to Rio: An Impossible Dialogue? ICTSD Report No.14. July.2012.

[11]. Overcoming Barriers to International Investment in Clean Energy, OECD report, 2015, p. 3. 